\title{
Study of the micro-crack growth in the concrete material to predict its lifetime
}

\author{
Manh Van Nguyen* \\ Hanoi University of Mining and Geology, Hanoi, Vietnam
}

\begin{abstract}
ARTICLE INFO
Article history:

Received 5th Jan. 2021

Revised $10^{\text {th }}$ Apr. 2021

Accepted 04th May 2021

Keywords:

Concrete,

Crack growth,

FLAC2D,

Micro-crack,

Lifetime.

\section{ABSTRACT}

The concrete always contains microstructures like micro-crack, voids, etc. These parameters affected the lifetime of materials. This article presents a computation algorithm to predict the lifetime of brittle materials like concrete which depends on the distribution of micro-crack in the materials. The proposed model is based on subcritical crack growth using the linear elastic fracture mechanics (LEFM) approach. The algorithm considers both tensile and shear fracturing. The proposed model was applied to a concrete sample under compressive loading for the prediction of a lifetime. The results showed a significant difference in failure zones and failure time under different magnitude compressive loadings and initial crack length.
\end{abstract}

Copyright (C) 2021 Hanoi University of Mining and Geology. All rights reserved.

\section{Introduction}

Concrete is the most widely used building material in the world. The concrete always contains microstructural like micro-crack, voids, etc. These parameters have a significant influence on the mechanical behaviour and lifetime of the concrete. When the concrete sample is under load, the micro-crack can develop and link to large cracks. Crack formation and development in materials will lose the functional safety of the structure. The micro-crack growth and time to failure of concrete material under load can be

${ }^{*}$ Corresponding author

E-mail: nguyenvanmanh@humg.edu.vn

DOI: 10.46326/JMES.2021.62(3).08 predicted by using damage and fracture mechanics.

Hillerborg et al., (1976) introduced a fictitious crack model based on a cohesive crack model (Dugdale, 1960; Barenblatt, 1962) for the crack propagation study of the unreinforced concrete beam. Thereafter, some fracture models have been proposed and used to predict the nonlinear fracture behaviour of cementitious materials. The other nonlinear models are crack band model (Bažant and Oh, 1983), twoparameter fracture model (Jenq and Shah, 1985), size-effect model [Bažant, 1984; Bažant et al., 1986), effective crack model (Nallathambi and Karihaloo, 1986), $\mathrm{K}_{\mathrm{R}}$-curve method based on 

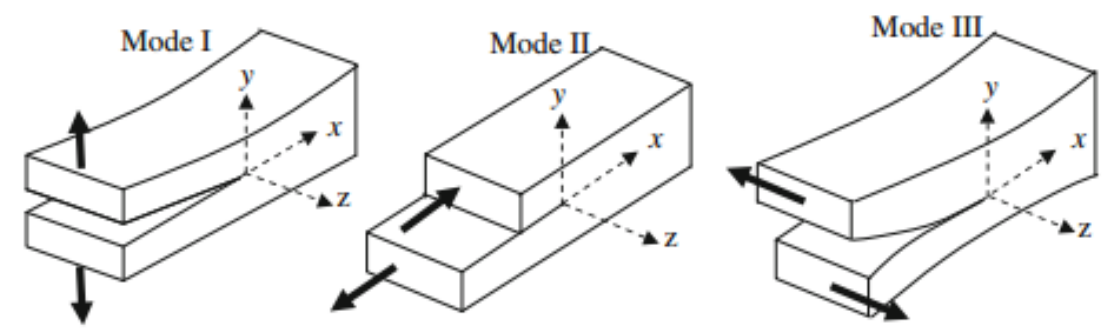

Figure 1. Cracking modes: mode I-opening, mode II-sliding or in-plane shear and mode III-the tearing or out-of-plane shear (Irwin, 1957).

cohesive force, double-K fracture model and Double-G fracture model $(\mathrm{Xu}$ and Reinhardt, 1998; Xu and Zhang, 2008).

\section{Crack model and stress intensity factor}

Mechanism of cracking and the crack propagation speed of concrete under load can be divided into three fundamentally different types of failure modes: mode I, mode II and mode III, as shown in Figure 1. However, combining two or three fundamental modes are more common in practice. For example, the cracking of the concrete beam under principle tensile stress has combined mode I and mode II. Therefore, to determine the stress state in the combination modes, each fundamental mode needs calculating.

The stress intensity factor was developed by (Irwin, 1957) and represented by the variable K. It is one of the most fundamental and useful parameters in all fracture mechanics. The stress intensity factor describes the stress state at a crack tip and is related to crack growth.

The stress intensity factor for mode I, mode II and mode III is denoted by KI, KII, and KIII. These factors are formally defined as:

$$
\begin{aligned}
& \mathrm{K}_{\mathrm{I}}=\lim _{\mathrm{r} \rightarrow 0} \sqrt{2 \pi r} \sigma_{\mathrm{yy}}(\mathrm{r}, \theta) \\
& \mathrm{K}_{\mathrm{II}}=\lim _{\mathrm{r} \rightarrow 0} \sqrt{2 \pi r} \sigma_{\mathrm{yx}}(\mathrm{r}, \theta) \\
& \mathrm{K}_{\mathrm{III}}=\lim _{\mathrm{r} \rightarrow 0} \sqrt{2 \pi r} \sigma_{\mathrm{yz}}(\mathrm{r}, \theta)
\end{aligned}
$$

Where: $\sigma_{y y}, \sigma_{y x}$ and $\sigma_{y z}$ - the stress distribution near the crack tip in polar coordinates $(r, \theta)$.

The stress intensity factor for a crack of length $2 \mathrm{a}$, at right angles, in an infinite plane is as follows:

$$
K_{I}=\sigma \sqrt{2 \pi a}
$$

$$
\begin{aligned}
& K_{I I}=\tau \sqrt{2 \pi a} \\
& K_{I}=\tau^{\prime} \sqrt{2 \pi a}
\end{aligned}
$$

Where: $\sigma, \tau$ and $\tau^{\prime}$ - normal stress, in-plane shear stress, and out-of-plane shear stress respectively.

The crack in the material begins to grow when the stress intensity factor $(\mathrm{K})$ reaches the fracture toughness (KC), which depends on the type of material and is determined through experiments. The fracture toughness of the concrete is varied $0.2 \div 1.4$ (Wikipedia).

\section{Crack propagation}

The crack propagation speed was proposed by (Charles, 1958) as follows:

$$
v=v_{o} K^{n} \exp \left(\frac{-u}{K_{b} T}\right)
$$

Where: $v_{o}$ - the material constant, $K$ - the stress intensity, $n$ - the the stress corrosion index, $u$ - the activation energy, $K_{b}$ is the Boltzmann constant, and $T$ is the absolute temperature.

For specific material types and under the assumption of constant temperature, equation (7) can be simplified into equation (8) as follows:

$$
v=C \cdot K^{n}
$$

Where: $C$ - the fracture growth constant.

Besides fracture growth in tension, it has to consider also shear fracture growth. It is assumed that the resulting speed of fracture growth is the superposition of both components (tensile and shear loads) as given by:

$$
v=v\left(K_{I}\right)+v\left(K_{I I}\right)
$$

\section{Lifetime prediction}

Experiments have investigated the lifetime of solids under tensile load for a long time by many 
authors (Carus and Dasgupta, 1998; Eyring, 1936; Sulzer, 1976; Guedes, 2006). However, these studies are only suitable for brittle and substantial materials. It should be considered to the microcrack, voids, etc, better understand the lifetime of concrete material.

The subcritical crack growth simulation and lifetime prediction of the concrete material under load are based on the 2D finite-difference code FLAC (Itasca, 2019). The lifetime prediction of concrete material is based on the idea proposed by (Konietzky et al., 2009) for rocks under static load. It is assumed that each zone contains microcracks of different elongation according to a given probability distribution. The stress distribution for each zone will be calculated according to Mohr-Coulomb's constitutive law. The stress intensity factor for each zone is calculated for the corresponding micro-cracks according to equations (4) and (5). The subcritical crack growth velocity is calculated according to equations (8) and (9). If the critical stress intensity factor is reached or the crack length has reached the zone size, the zone fails and goes into the post-failure with loss of cohesion and tensile strength. The lifetime of a zone (tzone) can get by integration over the crack length as follows:

$$
t_{\text {zone }}=\int_{a_{o}}^{a_{c}} \frac{d a}{v}
$$

Where: $a_{o}$ and $a_{c}$ - the initial crack length and critical crack length, respectively; $v$ is the crack velocity according to equation (9).

The equation (7) can be rewritten by using equations (4), (5), (8), and (9) as follows:

$$
t_{\text {zone }}=\frac{1}{C\left(\sigma^{n}-\tau^{n}\right)}\left(\frac{2}{\pi}\right)^{n / 2} \frac{a_{c}^{1-n / 2}-a_{o}^{1-n / 2}}{1-n / 2}
$$

Where: $a_{c}$ - the critical crack length, given by the minimum of three entities: the critical length according to either $K_{I C}$ or $K_{I I C}$ or the zone edge length $d_{\text {zone }}$ as following:

$$
a_{c}=\min \left\{\frac{2}{\pi}\left(\frac{K_{I C}}{\sigma}\right)^{2} ; \frac{2}{\pi}\left(\frac{K_{I I C}}{\tau}\right)^{2} ; d_{\text {zone }}\right\}
$$

The numerical model consists of numerous zones, which are characterized by the MohrCoulomb's law and are therefore characterized by the following material parameters: Young's modulus, Poisson's ratio, cohesion, friction angle, and tensile strength. In addition, each zone has an initial micro-crack. The length of the micro cracks and their distribution in space can follow any stochastic distribution function. The numerical calculations are performed in the time domain. The time step $\Delta t$ is kept sufficiently small to allow stress re-distributions and to follow the crack growth in detail.

The actual crack length $a_{\text {new }}$ is obtained by time integration as follows:

$$
a_{\text {new }}=a_{\text {old }}+v \cdot \Delta t
$$

\section{Numerical simulation results}

The numerical model simulations were performed with the FLAC2D. The programming was done with the internal program language FISH. The concrete sample $0.6 \times 0.6 \mathrm{~m}$ in size was used for simulation of the uniaxial compression test. A mesh of $15 \times 15$ elements was used for the simulation means that each element has a size of $4 \times 4 \mathrm{~cm}$. Each element of the model contains a micro crack with an average length of $6 \mathrm{~mm}$ and a standard deviation of $1 \mathrm{~mm}$. The sample is under a compression load of $4 \mathrm{MPa}$. Table 1 shows the

Table 1. Concrete material parameters.

\begin{tabular}{|c|c|c|}
\hline Parameter & Unit & Value \\
\hline Young's modulus & $\mathrm{GPa}$ & 35 \\
\hline Poisson's ratio & - & 0.2 \\
\hline Density & $\mathrm{kN} / \mathrm{m}^{3}$ & 25 \\
\hline Cohesion & $\mathrm{MPa}$ & 4 \\
\hline Tensile strength & $\mathrm{MPa}$ & 1.5 \\
\hline Stress corrosion index $\mathrm{n}$ & - & 30 \\
\hline Fracture toughness, $\mathrm{K}_{\mathrm{IC}}$ & $\mathrm{MPa}^{1 / 2}$ & 1.0 \\
\hline Fracture toughness, $\mathrm{K}_{\mathrm{IIC}}$ & $\mathrm{MPa}^{1 / 2}$ & 1.0 \\
\hline Fracture growth constant, $\mathrm{C}$ & $(\mathrm{m} / \mathrm{s})\left(\mathrm{Pa}^{1 / 2}\right)^{-\mathrm{n}}$ & $10^{-169.6583}$ \\
\hline
\end{tabular}




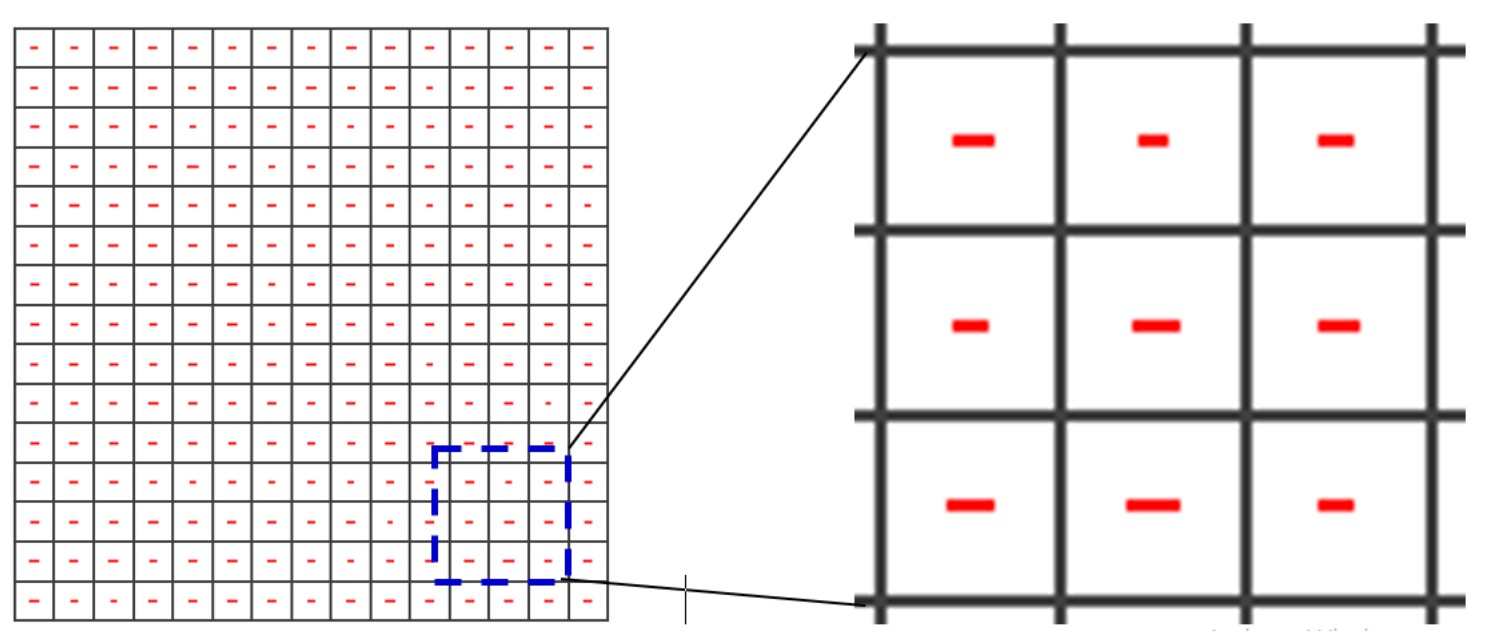

Figure 2. The distribution of initial micro cracks in the concrete model.

Table 2. The distribution of initial micro crack length for each element in the model (average: $6 \mathrm{~mm}$, standard deviation: $1 \mathrm{~mm}$ ).

\begin{tabular}{|c|c|c|c|c|c|c|c|c|c|c|c|c|c|c|c|}
\hline $\mathrm{j} \mid \mathrm{i}$ & 1 & 2 & 3 & 4 & 5 & 6 & 7 & 8 & 9 & 10 & 11 & 12 & 13 & 14 & 15 \\
\hline 15 & 5.99 & 5.12 & 6.11 & 6.76 & 6.19 & 4.82 & 6.62 & 4.44 & 7.74 & 6.87 & 6.17 & 6.69 & 5.55 & 5.94 & 7.60 \\
\hline 14 & 6.04 & 5.89 & 7.84 & 6.33 & 5.00 & 5.17 & 5.54 & 7.83 & 5.19 & 7.99 & 4.60 & 6.38 & 5.99 & 7.25 & 6.37 \\
\hline 13 & 6.41 & 7.04 & 6.10 & 5.30 & 4.43 & 4.72 & 6.33 & 5.44 & 4.43 & 4.90 & 5.03 & 5.15 & 5.01 & 6.55 & 5.07 \\
\hline 12 & 7.59 & 5.65 & 5.49 & 6.99 & 8.86 & 5.53 & 4.82 & 5.35 & 7.14 & 5.61 & 5.63 & 5.57 & 4.71 & 7.12 & 6.28 \\
\hline 11 & 5.18 & 7.66 & 6.31 & 7.52 & 5.81 & 5.40 & 5.80 & 4.23 & 5.95 & 4.97 & 4.74 & 5.42 & 6.49 & 4.32 & 4.19 \\
\hline 10 & 5.73 & 6.18 & 7.73 & 6.82 & 6.81 & 6.99 & 6.26 & 5.90 & 7.72 & 4.34 & 6.27 & 5.04 & 6.68 & 4.34 & 6.81 \\
\hline 9 & 6.30 & 6.02 & 5.48 & 4.85 & 6.73 & 7.06 & 4.59 & 4.43 & 6.37 & 5.57 & 5.65 & 5.79 & 4.65 & 5.44 & 5.39 \\
\hline 8 & 6.15 & 5.13 & 7.09 & 5.92 & 5.77 & 6.90 & 4.80 & 6.88 & 7.31 & 5.03 & 6.91 & 6.60 & 8.87 & 5.90 & 5.63 \\
\hline 7 & 5.48 & 6.41 & 6.88 & 5.34 & 7.44 & 4.53 & 5.79 & 7.01 & 6.09 & 6.96 & 4.77 & 7.51 & 6.00 & 4.92 & 5.87 \\
\hline 6 & 5.59 & 5.12 & 5.58 & 7.11 & 7.34 & 5.55 & 6.20 & 5.50 & 5.70 & 7.45 & 5.97 & 5.73 & 6.65 & 3.14 & 5.57 \\
\hline 5 & 6.89 & 6.82 & 6.38 & 6.64 & 5.73 & 5.43 & 7.09 & 4.32 & 5.20 & 7.37 & 4.99 & 7.09 & 6.24 & 7.06 & 5.69 \\
\hline 4 & 6.47 & 7.10 & 5.88 & 5.34 & 4.65 & 5.98 & 4.19 & 5.32 & 4.22 & 6.24 & 5.63 & 16.07 & 4.04 & $4.92 !$ & 4.93 \\
\hline 3 & 6.59 & 7.12 & 6.42 & 7.02 & 5.71 & 6.76 & 6.45 & 6.07 & 6.28 & 3.43 & 6.28 & 6.03 & 7.27 & 6.99 & 5.75 \\
\hline 2 & 7.18 & 7.02 & 7.64 & 4.62 & 6.73 & 8.27 & 6.23 & 5.58 & 5.01 & 5.30 & 5.81 & 18.38 & 8.47 & $\underline{5} .5 .5$ & 6.08 \\
\hline 1 & 7.88 & 5.63 & 4.23 & 6.58 & 5.61 & 7.82 & 5.64 & 6.26 & 5.63 & 7.32 & 6.15 & 6.76 & 6.43 & 6.72 & 6.38 \\
\hline
\end{tabular}

Table 3. Results of failure elements under compressive load.

\begin{tabular}{|c|c|c|c|}
\hline $\begin{array}{c}\text { Initial micro crack } \\
\text { length }(\mathrm{mm})\end{array}$ & $\begin{array}{c}\text { Standard } \\
\text { deviation }(\mathrm{mm})\end{array}$ & Failure time & $\begin{array}{c}\text { Failure elements } \\
\text { (element) }\end{array}$ \\
\hline 6 & 1 & 60 days 20 hours 20 minutes 51 seconds. & 30 \\
\hline 6 & 1 & 60 days 20 hours 27 minutes 10 seconds. & 50 \\
\hline 6 & 1 & 60 days 20 hours 29 minutes 38 seconds. & 65 \\
\hline
\end{tabular}

used concrete material parameters. The distribution of initial micro-cracks in the concrete model is shown in Figure 2 and Table 2 (Charles, 1958; Konietzky et al., 2009).

Figure 3 and Table 3 show that after 60 days 20 hours 20 minutes 51 seconds can be seen 30 failure elements. After that, the number of failure elements increased from 30 to 50 , with the time increasing 6 minutes 19 seconds. After 60 days 20 hours 29 minutes 38 seconds, the number of failure elements increase to 65 elements as observed in Figure 3. At that time, 


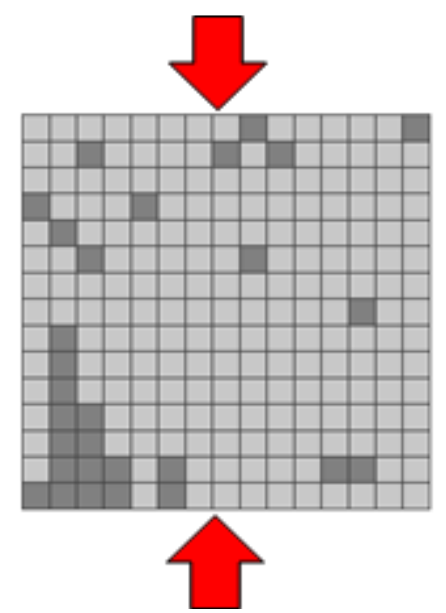

60 days 20 hours 20 minutes 51 seconds. Failure elements: 30

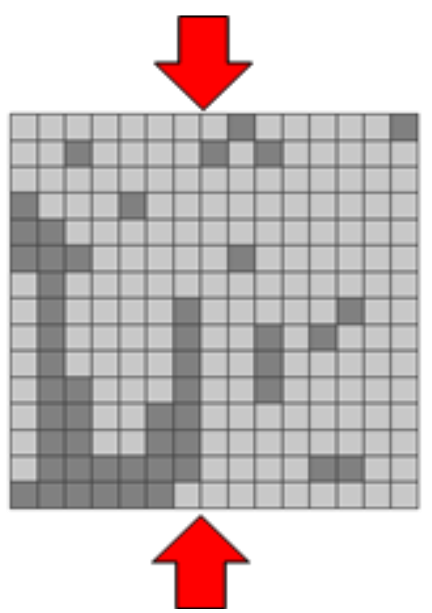

60 days 20 hours 27 minutes 10 seconds. Failure elements: 50

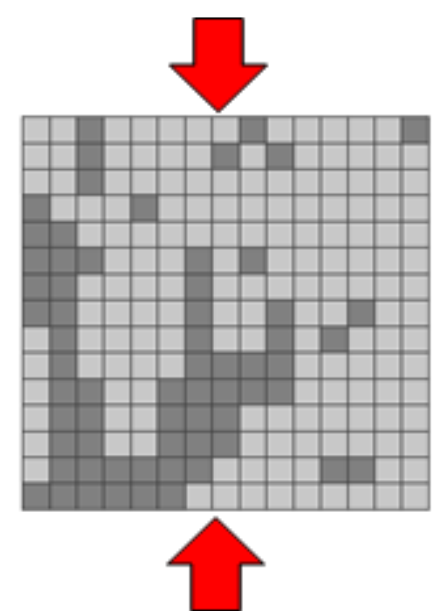

60 days 20 hours 29 minutes 38 seconds. Failure elements: 65

Figure 3. The crack propagation of concrete material under compressive load (black color is failured element).

the sample can be considered a failure because the crack has been propagated through the sample.

\subsection{Influence of the loading magnitude}

To study the influence of the loading magnitude, numerical simulation was conducted on the concrete sample with a dimension of $0.6 \mathrm{x}$ $0.6 \mathrm{~m}$. The initial micro crack length is $6 \mathrm{~mm}$ and a standard deviation of $1 \mathrm{~mm}$. The compressive loading is varied from 3.8 MPa to 4.0 and $4.2 \mathrm{MPa}$. The simulation results are shown in Table 4.
The numerical simulation results in Table 4 show that when the compressive loading increase from $3.8 \mathrm{MPa}$ to $4.0 \mathrm{MPa}$, the failure time is reduced from 2 years to 60 days with the same number of failure elements. It means that the failure time is decreased 12 times. However, when the compressive loading increased from 4.0 MPa to $4.2 \mathrm{MPa}$ the failure time for 50 failure elements is reduced from 60 days to 30 days ( 2 times).

\subsection{Influence of the initial crack length}

Table 4. The simulation results of failure elements under different compressive loadings.

\begin{tabular}{|c|c|c|c|}
\hline $\begin{array}{c}\text { Compressive loading } \\
(\mathrm{MPa})\end{array}$ & $\begin{array}{c}\text { Failure elements } \\
\text { (element) }\end{array}$ & Failure time & Type of failure \\
\hline 3.8 & 50 & $\begin{array}{c}\text { 2 years } 13 \text { minutes } 03 \\
\text { seconds }\end{array}$ & \\
\hline 4.0 & 50 & $\begin{array}{l}\text { 60 days 20 hours } 27 \\
\text { minutes } 10 \text { seconds }\end{array}$ & \\
\hline 4.2 & 50 & $\begin{array}{c}\text { 30 days } 10 \text { hours } 17 \\
\text { minutes } 23 \text { seconds }\end{array}$ \\
\hline
\end{tabular}


Table 5. Results of failure time with the different initial crack length (standard deviation: $1 \mathrm{~mm}$ ).

\begin{tabular}{|c|c|c|c|}
\hline $\begin{array}{c}\text { Initial crack length } \\
(\mathrm{mm})\end{array}$ & $\begin{array}{c}\text { Failure elements } \\
\text { (element) }\end{array}$ & Failure time & Type of failure \\
\hline 5 & 50 & 2 years 37 minutes 20 seconds & \\
\hline 6 & 50 & $\begin{array}{c}\text { 60 days 20 hours 27 minutes } \\
10 \text { seconds }\end{array}$ \\
\hline 7 & 50 & $\begin{array}{c}\text { 3 days 5 hours } 4 \text { minutes } 16 \\
\text { seconds }\end{array}$ \\
\hline
\end{tabular}

In order to study the influence of initial crack length on failure time of sample, the numerical simulation was conducted with the initial crack length of 5, 6, and $7 \mathrm{~mm}$ and a standard deviation of $1 \mathrm{~mm}$ under a compressive load of 4.0 MPa. The results of failure time for 50 elements and type of failure are shown in Table 5.

The results in Table 5 show that the failure time for 50 failure elements reduced 12 times with the initial crack length increasing from $5 \mathrm{~mm}$ to $6 \mathrm{~mm}$. In addition, the failure time for 50 failure elements reduced 20 times when the initial crack length increased $6 \div 7 \mathrm{~mm}$. Thus, it has shown that the initial crack length has significantly influenced the failure time of the sample under compressive loading.

\section{Conclusions}

The numerical calculation scheme for the lifetime prediction of concrete material has been proposed. The primary process modeled is the subcritical crack growth and coalescence of microcracks based on the linear elastic fracture mechanics. The proposed model was applied to the concrete samples under compressive loading for the prediction of failure time. The results show that there was a significant difference in failure zones and failure time under different magnitude compressive loadings and initial crack length. The failure time is significantly reduced (up to 20 times) with a little increase in compressive loading or initial crack length. However, the orientation of the initial micro-crack in this study was assumed that in the horizontal direction. So the further investigation is necessary to improve the modeling., including:

(i) The orientation and length of the microcracks at the initial state and the fracture process should be considered in the simulation.

(ii) Different mesh sizes and shapes type should be considered to incorporate distribution of the homogeneous areas.

(iii) The proposed procedure should be tested on more complex loading situations and it could be applied to practical applications in civil engineering.

\section{Acknowledgments}

The author thanks the anonymous reviewer for the hints and remarks, which have contributed to improving the quality of the paper.

\section{Author contributions}

Nguyen Van Manh study the conception and design draft of the manuscript, numerical simulation, and also analysis and interpretation of the results. The author has done all of the critical revisions. 


\section{References}

Barenblatt, G. I. (1962). The mathematical theory of equilibrium cracks in brittle fracture. Advances in Applied Mechanics, 7(1), 55-129.

Bažant, Z. P. (1984). Size effect in blunt fracture: Concrete, rock, metal. Journal of Engineering Mechanics, 110(4), 518-535.

Bažant, Z. P., Oh, B. H. (1983). Crack band theory for fracture of concrete. Materials and Constructions, 16, 155-177.

Bažant, Z. P., Kim J. K., Pfeiffer P. A. (1986). Determination of fracture properties from size effect tests. Journal of Structural Engineering ASCE, 112(2), 289-307.

Caruso, H., Dasgupta A. (1998). A fundamental overview of accelerated testing analytical models J.IEST., 41, 16-20.

Charles, R. J. (1958). Static fatigue of glass. Journal of Applied Physics, 29, 1549-1560.

Dugdale, D. S. (1960). Yielding of steel sheets containing slits. Journal of Mechanics and Physics of Solids, 8(2), 100-104.

Eyring, H. (1936). Viscosity, plasticity, and diffusion as examples of absolute reaction rates. Journal of Chemical Physics, 4, 283-291.

Itasca Consulting Group. (2019). FLAC manual. Minneapolis, Minnesota USA.

Guedes, R. M. (2006). Lifetime prediction of polymer matrix composites under constant or monotonic load. Composites, 37(Part A), 703- 715.

Hillerborg, A., Modeer, M., Petersson, P. E. (1976). Analysis of crack formation and crack growth in concrete by means of fracture mechanics and finite elements. Cement and Concrete Research, 6, 773-782.

https://en.wikipedia.org/wiki/Fracture_toughne ss
Irwin, G. R., (1957). Analysis of stresses and strains near the end of a crack traversing a plate. Journal of Applied Mechanics, Transactions ASME, 24, 361-364.

Jenq, Y. S., Shah, S. P. (1985). Two parameter fracture model for concrete. Journal of Engineering Mechanics ASCE, 111(10), 1227-1241.

Konietzky, H., Heftenberger, A., Feige, M. (2009). Life-time prediction for rocks under static compressive and tensile loads: a new simulation approach. Acta Geotechnica, 4, 73-78.

Nallathambi, $\quad$ P., Karihaloo, $\quad$ B. L., (1986). Determination of specimen-size independent fracture toughness of plain concrete. Magazine of Concrete Research 38, 67-76.

Sulzer, A. I. (1976). Der Zerstörungsvorgang in Festkörpern. In: Balarin $M$ (ed) Festkörperphysik Entwicklungstendenzen und Anwendungsmöglichkeiten. AkademieVerlag, Berlin, 224-247.

$\mathrm{Xu}, \quad$ S., Reinhardt, H. W. (1998). Crack extension resistance and fracture properties of quasi- brittle materials like concrete based on the complete process of fracture. International Journal of Fracture, 92, 71-99.

Xu, S., Reinhardt, H. W. (1999). Determination of Double-K criterion for crack propagation in quasi-brittle materials, part I: Experimental investigation of crack propagation. International Journal of Fracture, 98, 111-149.

Xu, S., Zhang, X. (2008). Determination of fracture parameters for crack propagation in concrete using an energy approach. Engineering Fracture Mechanics, 75, 4292-4308. 